\section{Cortical activation following chronic transcranial direct current stimulation in patients with minimally conscious state: A NIRS-based assessment associated to behavioral and plastic response}

Nicola Lamberti, ${ }^{1}$ Sofia Straudi, ${ }^{2}$ Valentina Bonsangue, ${ }^{2}$ Andrea Montis, ${ }^{2}$ Susanna Lavezzi, ${ }^{2}$ Francesco Bernardi, ${ }^{3}$ Giovanna Marchetti, ${ }^{3}$ Nicole Ziliotto, ${ }^{3}$ Veronica Tisato, ${ }^{4}$ Paola Secchiero, ${ }^{4}$ Fabio Manfredini,, ${ }^{1,2}$ Nino Basaglia ${ }^{1,2}$

${ }^{1}$ Department of Biomedical and Surgical Specialties Sciences, University of Ferrara; ${ }^{2}$ Unit of Physical and Rehabilitation Medicine, University Hospital of Ferrara; ${ }^{3}$ Department of Life Sciences and Biotechnology, University of Ferrara; ${ }^{4}$ Department of Morphology, Surgery and Experimental Medicine, University of Ferrara, Ferrara, Italy

\section{Background}

Near infrared spectroscopy (NIRS), a non-invasive technique measuring changes in brain tissue oxygenation, is potentially useful in the study of traumatic brain injury. ${ }^{1,2}$ In a longitudinal pilot study in patients with minimally conscious state (MCS) (NCT:02288533) we assessed by NIRS the changes of cortical activation (CANIRS) following chronic transcranial direct current stimulation (tDCS) and their association with behavioral changes and biomarkers of plasticity. ${ }^{3}$

\section{Methods}

Six male patients aged $35 \pm 10$ with posttraumatic chronic $(\geq 1$ year) MCS were enrolled to receive ten 40-minute daily sessions of $2 \mathrm{~mA}$ bilateral M1 anodal tDCS (Brainstim, EMS, Italy).

Before the first and last session, twentyminute NIRS monitoring was performed, with optodes placed at M1 bilaterally. Oxygenated hemoglobin was recorded, with area-under-curve calculated to determine CANIRS. Consciousness was assessed by the coma recovery scale-revised (CRS-R) total score. Two neuro-vascular biomarkers of plasticity (brain-derived neurotrophic factor and vascular endothelial growth-fac- tor) were quantified in sera samples by proper methods.

\section{Results}

CANIRS increased following treatment in the whole population $(+13 \%$; $\mathrm{P}=0.60)$ as well the CRS-R total score (from $11 \pm 3$ to $12 \pm 2$ ).

CANIRS, stable in four patients (mean fold-change 0.5 ), was selectively increased in two subjects (mean fold-change 2.2). Interestingly, only CANIRS responders showed an increase of CRS score $(\geq 2$ points) and variations of plastic biomarkers (Figure 1)
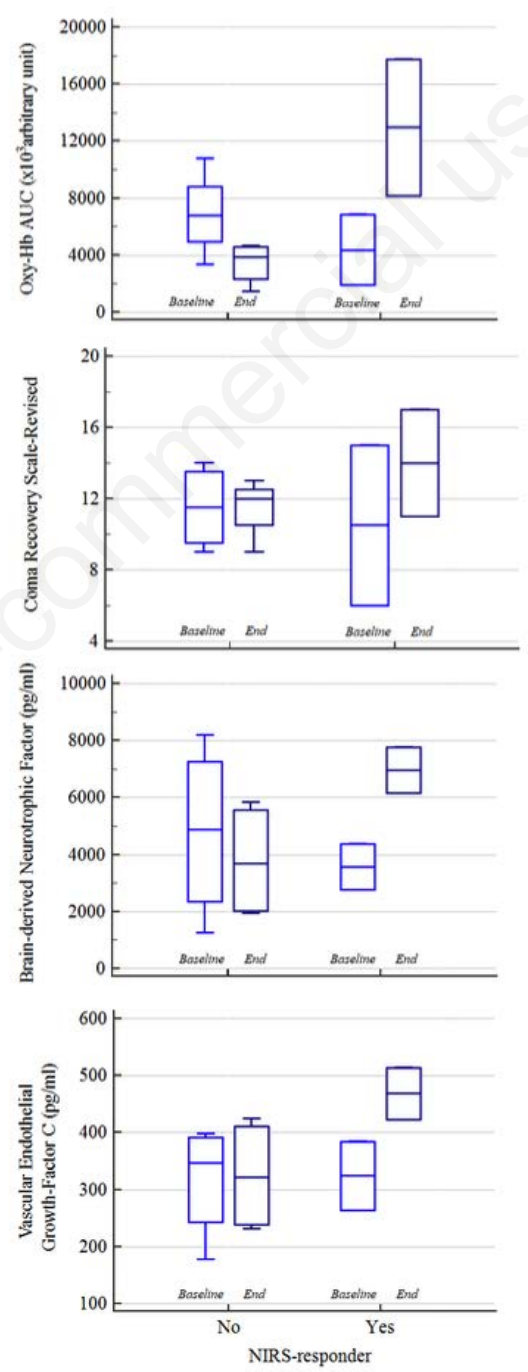

Figure 1. Values of $\mathrm{CA}_{\mathrm{NIRS}}$, CRS-R, BDNF and VEGF-C at baseline and at the end of the 10 sessions of $\mathrm{tDCS}$.
Correspondence: Nicola Lamberti, Department of Biomedical and Surgical Specialties Sciences, University of Ferrara, Ferrara, Italy.

E-mail: nicola.lamberti@unife.it

Key words: Neurovascular diseases; meeting.

Conference presentation: $9^{\text {th }}$ Annual Meeting of the International Society of Neurovascular Disease (ISNVD), May 30 $30^{\text {th }}-31^{\text {st }}, 2019$, Ferrara, Italy.

This work is licensed under a Creative Commons Attribution 4.0 License (by-nc 4.0).

(C) Copyright: the Author(s), 2019

Licensee PAGEPress, Italy

Veins and Lymphatics 2019; 8:8436

doi:10.4081/vl.2019.8436

\section{Conclusions}

The study, limited by the small sample size, supports the feasibility of NIRS monitoring in MCS patients. CANIRS, with variations congruent with behavioral and plasticity changes, may represent an objective technical biomarker of response to tDCS treatment.

\section{References}

1. Davies DJ, Su Z, Clancy MT, et al. Near-infrared spectroscopy in the monitoring of adult traumatic brain injury: a review. J Neurotrauma 2015;32:933-41.

2. Tessari M, Malagoni AM, Vannini ME, et al. A novel device for non-invasive cerebral perfusion assessment. Veins and Lymphatics, 2015;4:4650.

3. Straudi S, Bonsangue V, Mele S, et al. Bilateral M1 anodal transcranial direct current stimulation in post traumatic chronic minimally conscious state: a pilot EEG-tDCS study. Brain Inj 2019;33:490-5. 